\section{Shortcircuit leads India to abandon Internet satellite}

[NEW DELHI] India's newest telecommunications satellite, INSAT-2D, launched only four months ago, has been abandoned following a series of problems resulting from a shortcircuit in its onboard power supply. The Indian Space Research Organization (ISRO) in Bangalore said in a statement that "the satellite has now become inoperable".

The US\$50-million INSAT-2D, the fourth in a series designed and built by ISRO, was launched by Europe's Ariane rocket in June. Its loss is a major blow to India's plans to expand Internet services and provide telephone links to remote areas.

The mishap has come at a time when ISRO is already struggling to correct the orbit of a remote-sensing satellite, IRS-1D, launched two weeks ago (see Nature 389, $432 ; 1997)$. After an apparently perfect launch, ISRO's Polar Satellite Launch Vehicle placed the satellite in an elliptical path, bringing the spacecraft to within $300 \mathrm{~km}$ of Earth, instead of placing it in the circular orbit necessary for remote sensing.

ISRO has managed to push the perigee to $400 \mathrm{~km}$, and says that it is confident that it can increase it further to a circular orbit from which it will be able to carry out most of its remote-sensing functions. K.S.Jayaraman

\title{
Asia-Pacific forum backs life science network
}

[TOKYO] A move by life scientists in the Asia-Pacific region to form a network to promote biotechnology and biomedical research has won strong political endorsement from the Asia-Pacific Economic Cooperation (APEC) forum (see Nature 388, 3; 1997).

At a meeting of APEC's working group on industrial science and technology in Singapore last week, a motion by South Korea to support the network won backing from eight APEC members: Japan, Australia, Singapore, Malaysia, the Philippines, Indonesia, Thailand and Taiwan.

Gurinder Shahi of the International Vaccine Institute in Seoul, who attended the meeting as a representative of the secretariat of the proposed International Molecular Biology Network for Asia and the Pacific Rim, says delegates from the United States and New Zealand also informally expressed support.

APEC's endorsement will not automatically be translated into financial backing, as the forum operates on a very limited budget. But it will give the network the political authority to begin work on a draft intergovernmental agreement, modelled along the lines of that setting up the European Mole- cular Biology Organization (EMBO), many of whose characteristics the new network hopes to emulate.

Even with APEC's support, the experience of the vaccine institute suggests that it could take a long time to establish and ratify such an agreement. Meanwhile, funds are being sought from other sources - perhaps some of the institutes in the region that have expressed their support, as well as the private sector.

A task force of seven scientists from Japan, South Korea, Taiwan, Singapore, China, Hong Kong and New Zealand will meet next month in Shanghai, at the Institute of Biochemistry of the Chinese Academy of Sciences, to discuss fund-raising and future strategy.

The network's founding members favour membership based on individuals selected for their excellence, rather than on institutions, as initially proposed at a meeting in Tokyo in June. Each country will probably propose about 10 members, and EMBO may be called in to advise on the final membership list. Shahi says it is hoped that the membership issue will be settled before a conference is held by the network in South Korea next June.

DavidSwinbanks

\section{Head of Third World biotechnology centre in Delhi resigns}

[NEW DELHI] The International Centre for Genetic Engineering and Biotechnology (ICGEB) is looking for a new head for its New Delhi component, following the resignation of Krishna Kumar Tewari from the post he has occupied since the unit was set up a decade ago.

Although his term expires next June, Tewari says he has resigned now to give the centre more time to choose his successor. But another factor appears to have been the tension between Tewari and the Indian government over his teaching commitments at the University of California at Irvine.

Tewari's departure was announced during a meeting last week of ICGEB's council of scientific advisers, held to review the centre's research activities in New Delhi and its twin component in Trieste, Italy.

Despite Tewari's surprise departure, ICGEB officials were upbeat last week. "The centre, which was created amidst much scepticism and mistrust, is now a centre of excellence," says director Arturo Falaschi. Forty-one countries are full members of ICGEB, and 200 scientists from 31 countries work in its two laboratories.

The centre plans to celebrate its tenth anniversary with a symposium in Trieste in November. "ICGEB has now reached a stage where it can demonstrate that basic research carried out at its two laboratories can be exploited," says Xiaocheng Gu of the College of Life Sciences of Peking University, Beijing, who chaired last week's meeting.

Products awaiting field trials include an antimalaria peptide vaccine and an insectresistant rice plant. A technique for producing cheap recombinant hepatitis-B vaccine will soon transfer to industry.

ICGEB trains 400 scientists from developing countries each year. And ICGEBnet, a central biocomputing resource in Trieste, provides links with 874 scientists in member countries via the Internet.

According to Falaschi, funding has improved to a point where "we are sure of maintaining the current level of activities for at least five years". But he says one weak point is the inability to obtain support from industrialized countries. Another worry is the substantial funds that will be needed to replace equipment and to expand laboratory space over the next two or three years.

Tewari had been chairman of the molecular biology and biochemistry department

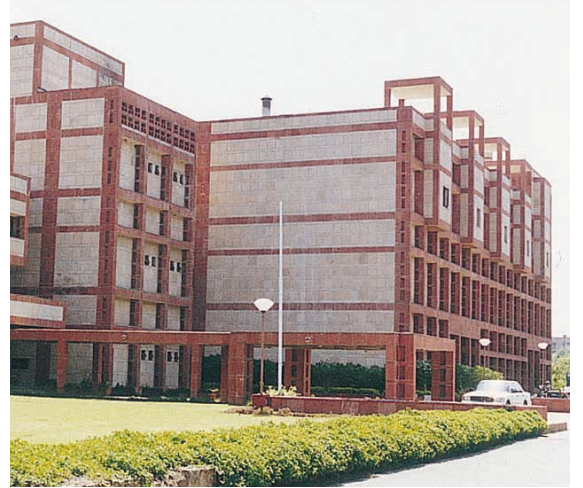

ICGEB in New Delhi (above) has a twin centre in Trieste, and seeks to expand its funding base.

at Irvine for 15 years when he was appointed to head ICGEB's Indian unit. He says he will return to Irvine.

Although Tewari's direct approach to management has long irked government bureaucrats, his main problems began in May when the Department of Biotechnology objected to his spending four to six months a year teaching at Irvine. Tewari denies that his laboratory suffered from his absence, and says that ICGEB has benefited from his international connections.

K. S.J. 